\title{
Caleidoscópio biográfico: leituras de Juscelino Kubitschek de Oliveira
}

\author{
Ana Maria Ribas Cardoso ${ }^{1}$
}

\begin{abstract}
Resumo: $\mathrm{O}$ artigo diz respeito à dimensão político-cultural dos Anos $\mathrm{JK}$, através da revisitação das biografias do presidente da República Juscelino Kubitschek que narram história(s) na perplexidade do tempo de uma vida. Sob uma abordagem teórico-metodológica que sublinha os vínculos entre história, memória, política e cultura, esse trabalho investiga uma determinada leitura do presente futuro passado pari passu à construção desse homem público e, a ela correlata, as estratégias de afirmação e conservação da sua memória. Por seu turno, o historiador deve examinar a(s) escrita(s) desta história e problematizar a memória que ornamenta esse passado para sacralizá-lo. Logo, investigar este período, a partir desses pressupostos, no tempo longo ainda tão caro ao ofício do historiador, faz compreender como práticas e vivências político-culturais tecem e determinam nossas vidas, quer privadas, quer públicas, ousando enfrentar o presente e rascunhar uma outra história.
\end{abstract}

Palavras-chave: História. Memória. Biografia.

[...] lemos para esquecer e também lemos para não esquecer. Escrevese para esquecer. E o efeito da escritura é fazer com que os outros não esqueçam. Escreve-se para lembrar e amanhã outros vão ler essa lembrança.

Beatriz Sarlo (2005, p. 6)

O percurso deste artigo revisita, nos (des) encontros entre história e memória, as biografias de Juscelino Kubitschek de Oliveira, tendo como pano de fundo o discurso que o naturalizou como "grande homem público", guardião da democracia em uma conjuntura de grave instabilidade política e fundador do novo ${ }^{2}$ Brasil. A proposta conflui para o exame do processo político-cultural, a um só tempo individual e coletivo, de elaboração da história desse passado - aqui tomado como espaço de reflexão - na perspectiva de um inquietante trabalho de rememoração e luto (Cf. AVELAR, 2003, p. 235-259). Subjazem indagações de como e por que esse passado vem sendo ressignificado, com base em estratagemas de

\footnotetext{
${ }^{1}$ Doutora em História Política (UERJ), com a tese Juscelino Kubitschek: profeta da modernidade, arquiteto do futuro?! e Professora de História do Colégio Pedro II, RJ. Parecerista da revista Encontros e membro do Programa de Residência Docente ligado à Diretoria de Pesquisa e Pós-Graduação (em parceria com a CAPES) do Pedro II. Colaboradora na área de Humanas do Instituto Nacional de Estudos e Pesquisas Educacionais Anísio Teixeira (INEP). E-mail: anaprofa@terra.com.br.

${ }^{2} \mathrm{O}$ novo como expressão política dos Anos JK serve para indicar a enunciação discursiva do que se imaginava um tempo melhor do que o anterior, portanto, que pressupõe "novas experiências que jamais haviam sido experimentadas dessa maneira, ganhando uma dimensão que confere ao novo um caráter de época" (Cf. KOSSELECK, 2006, p. 274).
} 
conservação e mecanismos de lembrança/esquecimento que guardam, pela dupla via da inscrição/desaparição, a memória (em disputa) desse sujeito histórico.

Compreendidas enquanto fonte e objeto de estudo da história, as biografias desvelam como experiências humanas individuais no tempo se mesclam ao coletivo, o que traz as marcas dos acontecimentos históricos, et pour cause, evidenciam como à memória pessoal/familiar se imbrica, simbólica e politicamente, a memória nacional. Se reconhecermos que tais escrituras representam uma instância socialmente construtora (e legitimadora) do homem e de sua obra, a elas correspondem narrativas que se constituem em espaços formadores do trabalho artesanal da memória - memória do nome, da experiência pessoal, da trajetória política, dos cinco anos de governo e, até mesmo, da própria autobiografia ${ }^{3}$.

Portanto, dado que as biografias de Juscelino Kubitschek são testemunhos históricos, convém, seguindo a proposta benjaminiana (1994), lê-las a contrapelo, contra a intenção de quem as produziu. Pois os artesãos desses discursos são homens que se comprometeram a narrar o que viram e/ou vivenciaram, selecionando, reunindo e interpretando fatos e informações - conforme códigos herdados de sua cultura, sentimentos e paixões políticas tendo em vista forjar leituras do presente do passado e dele se aproximar. Em que pese os limites entre vivenciado/sentido e narrado/reconstituído a permear qualquer escritura, biográfica, histórica ou literária, qual seja, tal questão conflui para o aceite de temporalidades sociais diversas, ao invés de supor uma hierarquia entre passado, presente e futuro que lê a história de forma conservadora.

Enquanto estratégia para trabalhar as fontes, algumas indagações foram elaboradas e se constituíram essenciais para trilhar o processo de afirmação e difusão da memória de Juscelino Kubitschek. Quem foram e/ou ainda são os biógrafos de Juscelino Kubitschek? Como as biografias reproduzem o corpus identitário de Juscelino Kubitschek forjado na autobiografia? Como as biografias dispõem fatos e ordenam a vida de JK para construir a sua persona carismática, empreendedora e democrática? De que maneira as escrituras biográficas sacralizam a memória desse homem público?

Diante da densa produção de textos (escritos, midiáticos e imagéticos) sobre Juscelino Kubitschek, optamos por uma abordagem metodológica que selecionou, por amostragem, as biografias que consideramos mais relevantes - Assis Barbosa (1988); Claudio Bojunga (2001); Heitor Cony (1982; 2002); Ronaldo Costa Couto (2001); Affonso Heliodoro (2005) -,

\footnotetext{
3 Referimo-nos aos três volumes autobiográficos de JK: Meu caminho para Brasília: a experiência de humildade. Rio de Janeiro: Bloch, 1974, v. I; Meu caminho para Brasília: a escalada política. Rio de Janeiro: Bloch, 1976, v. II; e Meu caminho para Brasília: 50 anos em 5. Rio de Janeiro: Bloch, 1978, v. III.
} 
cotejando-as entre si a partir de um corpus identitário já enunciado e ajuizado na autobiografia, a transitar do ex-presidente da República, democrata, pacificador e guardião das instituições, depois cidadão "injustiçado" pela ditadura militar ao "pobre menino Nonô" do interior das Minas Gerais. Desta forma, as escrituras biográficas de o(s) Juscelino Kubitschek convergem, com nomenclaturas diferentes, acentos variados e acréscimos, para os mesmos eixos da autobiografia, quais sejam: da infância do menino Nonô ao seminarista; da partida de Diamantina rumo à capital Belo Horizonte; do ingresso na Faculdade de Medicina ao diploma de doutor; da viagem à Europa; da entrada na vida política do país à presidência de República, e da cassação, do exílio e da única eleição perdida na ABL até ao mortal acidente automobilístico, seguido da entrada de JK no panteão. São eixos que, ao enlaçar, em uma retórica canônica, vida e morte expressam, na intercessão de múltiplas temporalidades, certa maneira de apre(e)nder e ler esse passado.

Assim, tais narrativas colocam, por um lado, o acento na ascensão de um homem de origem social humilde que se projetou na vida pública do país, compondo a tríade jovem telegrafista audacioso; médico urologista acadêmica e profissionalmente brilhante; e político, por talento e vocação. Por outro, descrevem JK como exemplo de chefe de Estado que se tornou símbolo de um novo Brasil: ora qualificam o governo Kubitschek como um momento ímpar de vitórias e crescimento econômico, ora superdimensionam os desdobramentos oriundos da cassação e do ostracismo político.

A princípio, importa retomar - enquanto tema biográfico relevante - o enaltecimento da personalidade materna, no que tange ao comportamento austero e rigoroso, à absoluta dedicação ao trabalho e às ações disciplinadas na formação do "grande homem" vis-à-vis a presentificação da ausência do pai através da verve alegre, teimosa e boêmia do temperamento. Mais Kubitschek, menos Oliveira - eis uma marca da identidade do presidente da República a ser legada à posteridade. Moldado pela mãe, Júlia Kubitschek, ou escolhido pelo próprio filho, vale ressaltar que esse referencial autobiográfico se manteve nas biografias:

[...] os que se admiravam com o sobrenome Kubitschek de dona Júlia - o qual ele também escolheu para carregar ao longo da vida, ficando conhecido como Juscelino Kubitschek ou simplesmente JK [...] (CONY, 2002, p. 18).

João César foi a lava - o temperamento. Júlia - o molde, a fôrma, o cânon. Juscelino não escolheu se tornar Kubitschek em vez de Oliveira. D. Júlia moldou-o Kubitschek. Esse 'enquadramento' das tendências hedonísticas e dissipadoras herdadas do pai é uma das chaves de sua personalidade. Júlia foi o ingrediente centro-europeu, de sangue eslavo e disciplinada cultura 
germânica combinados com a tradição luso-sedentária e pé-de-boi da professora. Foi a severidade, o recato, a pertinácia, a teimosia, a caturrice, o longo prazo, o esforço diuturno, a resistência, a sobrevivência (BOJUNGA, 2001, p. 39).

Enfatiza-se, outrossim, que as biografias convergem para uma questão social relevante para o historiador, qual seja: Juscelino logrou conseguir a nomeação de telegrafista graças a uma rede de sociabilidades, parcialmente herdada e/ou sabiamente construída a serviço de seu projeto pessoal, que é inteligível no contexto das práticas políticas do mandonismo local associadas ao coronelismo que há muito fincaram raízes na sociedade brasileira. Até porque, no interior de uma sociedade historicamente moldada pela escravidão, em que a ascensão social se afigurava restrita para a maioria da população, colocar-se sob a proteção e/ou obter algum favor de outrem poderoso ou superior eram estratégias de dominação de uma elite. Essa elite branca proprietária não prescindia das relações de interdependência do favor e, a estas coligada, exercia e legitimava o seu poder, por meio do qual conformava o lugar do indivíduo em suas tramas com o coletivo, estabelecendo um código cultural que normatizara a ordem social.

A colação de grau em Medicina representou, segundo os biógrafos, um marco no projeto pessoal de Juscelino Kubitschek, o que o "encorajou”, não ao acaso, a se aproximar de Sarah Luísa Gomes de Sousa Lemos. Moça oriunda de família tradicional e rica da cidade de Belo Horizonte, portanto nascida em "berço de ouro", 4 abria ao jovem médico recém-formado a possibilidade de galgar mais um degrau em direção ao topo do edifício social. Mas não só à ambição de integrar o restrito "círculo dos bem nascidos" ou o pequeno universo de famílias influentes, existia o desejo de apre(e)nder, por força da tradição familiar de Sarah, as artimanhas da política. Da narrativa de Claudio Bojunga:

A noiva de Juscelino, Sarah de Souza Lemos, integrava pelo lado paterno o clã dos Lemos, que se projetara desde o começo do Império [...]. A mãe de Sarah, dona Luísa Negrão, era filha do comendador José Duarte da Costa Negrão, rico proprietário da área onde fica o bairro de Floresta, em Belo Horizonte. O pai, ex-deputado Jaime Gomes de Souza Leite, havia representado Minas no Congresso durante 30 anos [...]. Uma das irmãs de Sarah, Amélia, casou-se com Gabriel de Resende Passos, em 1929 [...]. Uma outra desposou o deputado Júlio Bueno Brandão, filho do velho Bueno Brandão, ex-presidente do estado. A irmã Maria Luísa era esposa do deputado Clovis Pinto. Era a parentela mineira em todo o esplendor: o casamento de Juscelino Kubitschek com Sarah teria reflexos favoráveis na absorção do jovem médico pela tradicional família mineira.

\footnotetext{
${ }^{4}$ Expressão já utilizada no capítulo 2 de Kubitschek, 1974, p. 62.
} 
$[\ldots]$

O casamento representou para Juscelino ascensão social e admissão na grande família mineira. Não houve cálculo político - sua carreira começaria mais tarde. Mas ocorreu maior entrosamento social num meio mais impenetrável do que poderia parecer à primeira vista [...] (BOJUNGA, 2001, p. 88-9; 870-1).

Os textos biográficos transmitem, em geral, o quanto Juscelino Kubitschek, ajudado por seu cunhado e amigo Júlio Soares, prosperou na clínica médica, o que lhe permitiu avançar em seu projeto pessoal, inclusive no que tange à possibilidade de uma viagem à Europa, aos 28 anos, que era entendida como marca dos "bem-nascidos". Sem desconsiderarem essa versão, os biógrafos Assis Barbosa e Claudio Bojunga contam que a viagem se concretizou materialmente graças à confluência de outros fatores, dentre os quais contou aquela rede de sociabilidades cuidadosamente construída pelo sujeito histórico JK. E mais - escrever/ler o homem menino sempre inquieto, que apelava ao novo e ansiava maior experiência capaz de entrelaçar medicina e conhecimento do mundo, forjara traços identitários que, em última instância, respaldaram a trajetória ascensional dele. Vejamos:

[...] A inquietude antes fortaleceria em seu espírito a consciência de que era preciso fazer alguma coisa que o tirasse do ponto morto profissional, alguma coisa no sentido não apenas de aprimorar a sua arte de médico, como de conhecer o mundo, adquirir maior experiência de vida, sentir os problemas da medicina em perspectiva ampla. Era o mesmo apelo da adolescência, que o impulsionara a deixar a sua Diamantina. Homem feito, com vinte e sete anos, o apelo se desdobrava, agora, ganhava contornos nítidos. A ideia de uma viagem à Europa, a princípio acalentada em silêncio, foi recebida como rematada loucura, quando Juscelino decidiu fazer a comunicação aos seus familiares. Só os ricos ou protegidos do governo é que se davam ao luxo de se aperfeiçoarem no exterior [...]. Tentasse a experiência. Vendesse o automóvel. Com a importância apurada, somada às suas economias, completasse com um empréstimo bancário as despesas de viagem [...]. (BARBOSA, 1988, p. 281).

A interpretação dos biógrafos acerca da entrada de Juscelino na vida política e partidária merece certas considerações. A começar pela narrativa de Assis Barbosa, que se encerra nos anos $1930^{5}$, o acontecimento demarcou o início de uma nova etapa na vida para Juscelino Kubitschek. Como cirurgião da Força Pública, no sul de Minas Gerais, ele conseguiu ali, entre mortos e feridos, alicerçar a sua futura carreira política quando conheceu o líder do Partido Social Democrático (PSD) mineiro, Benedito Valadares, que teve um papel fundamental na

\footnotetext{
${ }^{5} \mathrm{O}$ segundo volume da biografia, a recobrir a trajetória política, ficou por se fazer, devido aos desdobramentos do regime militar, inclusive por força da cassação de JK.
} 
sua formação como homem público. A mesma se iniciou com um convite para a chefia do Gabinete Civil do governo de Minas Gerais, em 1933, durante a gestão de Valadares como interventor federal, e prosseguiu com a nomeação de JK para a prefeitura de Belo Horizonte, no dia 14 de abril de 1940, durante o Estado Novo. Esclarece-se, pois, a metáfora desse biógrafo: "Para Juscelino, a revolução paulista significa a sua primeira e grande experiência política. Juscelino receberia, com a campanha de 1932, além do batismo de fogo, o batismo da política" (BARBOSA, 1988, p. 320).

Quanto à concordância de Juscelino Kubitschek de se tornar, por indicação, prefeito de Belo Horizonte, pauta-se uma breve reflexão em torno das leituras dos biógrafos acerca desse fato. Aceitar ser nomeado para um cargo eletivo da administração pública implica uma violação às regras da democracia, pois a ditadura de Getúlio Vargas suspendeu as eleições nas três instâncias do poder e fechou o Congresso Nacional, o que configura um hiato na propalada tradição democrática do sujeito histórico Juscelino Kubitschek. Ao invés de questionarem essa postura política, os biógrafos optaram por ora justificá-la, grifando o caráter administrativo do cargo acima e as clivagens políticas; ora silenciá-la; ora enaltecê-la no que diz respeito à administração do "prefeito furacão" realizada na capital mineira. Desculpar sempre! Das leituras de Heitor Cony e Affonso Heliodoro:

Como prefeito, Juscelino foi obrigado a saudar o presidente. E o fez de maneira discreta, sem a menor alusão à situação política nacional: Estado Novo, crise da democracia - pontos polêmicos da política de Vargas com os quais Juscelino não se sentia afinado nem comprometido [...] (CONY, 2002, p. 50).

Prefeito de Belo Horizonte, JK realiza obra notável, que seu prestígio é projetado até para fora do país [...] Abre todas as saídas da capital mineira, constrói moderna rede de esgotos, canaliza água. Cria diversos bairros, abre rede subterrânea de luz e telefone, esburaca toda a cidade, transforma-se no 'Prefeito Furacão' ou 'Prefeito Tatu'.

[..]

Mas, sobretudo, urbaniza o bairro da Pampulha, onde cria seu famoso lago. Para urbanizá-lo chama grandes artistas como Oscar Niemeyer, Portinari, Ceschiatti e Burle Marx. [...] As atividades de JK à frente da Prefeitura de Belo Horizonte o credenciaram a concorrer às eleições para governador do Estado (HELIODORO, 2005, p. 131-132).

Se os biógrafos não puderam desconhecer a inflação, o desequilíbrio da balança de pagamento, o déficit público e/ou a estrita dependência do país ao capital e tecnologia estrangeiros que foram resultados da epopeia desenvolvimentista, eles não deixaram, por sua vez, de enfatizar as conquistas que marcaram os cinco anos da gestão Kubitschek. As 
narrativas sublinharam, propositalmente, as transformações econômicas ligadas à industrialização acelerada, bem como as novidades estético-culturais que redefiniram a sociedade brasileira na segunda metade dos anos 50. Inclusive, porque supunham concretizar o novo Brasil em detrimento das contradições engendradas pelo projeto modernizador desenvolvimentista. Das biografias:

[...] parecia que o Brasil finalmente dava certo. Apesar de algumas turbulências, foi uma festa de liberdade e desenvolvimento, sob a bandeira da ordem e progresso. Democracia a pleno vapor, economia em disparada, industrialização galopante. Brasília brotando do nada e enterrando sentimentos de inferioridade no chão bruto de cerrado, rodovias e ferrovias rasgando o interior, o Plano de Metas carreando realizações com energia. Mesmo com a inflação em alta, o auge do encantamento talvez seja 1958. [...] Liberdade, criatividade e uma quase euforia. Desenvolvimento, otimismo, horizontes abertos, muita esperança e fé no Brasil, que era feliz e sabia. Anos JK, anos dourados. Se assanhou a inflação, o governo Kubitschek também sacudiu o impávido colosso, acordou o gigante pela própria natureza no berço esplêndido (COUTO, 2001, p. 245).

Assim, a mais notável obra de Juscelino foi a criação de uma nova consciência para o brasileiro: forte, seguro de suas potencialidades, capaz, orgulhoso, determinado, crente e esperançoso no futuro do Brasil. A obra de JK, toda voltada para o homem, certamente, tirou-nos daquela postura dependente e mesmo subserviente em que vivíamos [...]. JK fez o Brasil crer-se uma grande nação, com um grande povo e um futuro grandioso à sua frente. (HELIODORO, 2005, p. 30).

"Metassíntese" do Plano de Metas, por ser responsável pela integração do país e, especialmente, emblema do novo Brasil moderno, graças à imaginada ação providencial do presidente da República, a cidade de Brasília ocupou um lugar relevante em todas as biografias por representar grosso modo o desfecho da obra desenvolvimentista de JK. Além do dispositivo constitucional, a transferência da capital para o planalto central, no âmbito do nacional-desenvolvimentismo, era encarada como uma maneira de transformar a cidade em um polo de atração em direção ao interior - atrasado e pouco povoado - permitindo, junto a outras medidas (a exemplo de rede de transporte e energia), o crescimento econômico até então marcadamente litorâneo e minimizando as disparidades regionais. Sendo assim, a nova capital federal, ao coroar de êxito a experiência pessoal/coletiva do chefe de Estado, foi (bio) grafada enquanto ícone da modernidade, por vez ainda reforçada pela arrojada arquitetura de Oscar Niemeyer - o "Michelangelo de JK" - que colocara o país na vanguarda mundial. Das palavras de Heitor Cony:

\footnotetext{
${ }^{6}$ Expressão utilizada por Juscelino Kubitschek ao se referir ao arquiteto e amigo Oscar Niemeyer. Citado por Bojunga (2001).
} 
Prevista na primeira Constituição republicana, a de 1891, sonhada pelos Inconfidentes Mineiros e adiada por todos os governos, Brasília marcaria definitivamente a imagem de JK na história do Brasil e na própria história do século 20 (CONY, 2002, p. 88).

A unificar todas as biografias, importa mencionar que determinadas qualidades humanas - coragem, espírito conciliador, habilidade, otimismo, determinação, inteligência, generosidade, disposição, simplicidade, dentre outros - idealizaram Juscelino Kubitschek. Era preciso (re) elaborar, com o mínimo de fraturas, a sua identidade, tendo como pano de fundo os desdobramentos políticos e ético-morais decorrentes da cassação, da prisão e do exílio pós64 que, à revelia, baniram JK da vida pública e do jogo político.

Desse modo, era imprescindível - para além da violência institucionalizada pelo Estado autoritário - sublinhar o sofrimento, a humilhação e o isolamento que os biógrafos acreditaram ter pesado, injustamente, sobre JK nos últimos anos de sua vida. Logo, caberia, por meio de uma escrita do luto, recompor o que faltava e mostrar os danos irreversíveis que o regime militar causou à vida dele nas dimensões privada e pública. Enfim, (re)constituir a persona e a sua história, enquanto denúncia e restituição. As interpretações de Heitor Cony, Costa Couto e Affonso Heliodoro comprovam a relevância do tema na construção de o Juscelino Kubitschek:

No dia 8 de junho são cassados os direitos políticos e o mandato de senador do cidadão Juscelino Kubitschek de Oliveira [...].

$[\ldots]$

O Nonô de Diamantina, o menino descalço que subia as ladeiras coloniais do velho Tijuco dos antigos faiscadores, é agora um homem completo: começa a descer as ladeiras - também não se importa -, terá sempre em suas retinas a amplidão do grande horizonte que criou e contemplou. Sem queixa, escoltado por militares que tiraram suas ramas dos coldres para manter o povo distante dele, JK embarca num avião da Ibéria. Amanhece em Madri. O dia - 14 de junho de 1964 - é apenas o primeiro de um exílio que ele saberá suportar com tristeza e dignidade (CONY, 1982, p. 86).

O poeta da ação e mito político vivo está ali solitário, carregando mala e dores. Oh, Brasil! Desde a brutal cassação de 8 de junho de 1964 sua vida murchara. Sobretudo nos três anos de exílio, um suplício, e nos anos 70, a provação constante do corpo e da alma [...]. Os problemas de saúde de JK eram antigos.

[...] E todos os dias, ao acordar, é o cidadão Juscelino Kubitschek de Oliveira quem está irremediavelmente só diante do fardo doído e doído do passado e do peso descomunal do futuro sem esperança, sem projeto político, sem desafio profissional, sem as principais alegrias da vida. Sem graça. Um martírio (COUTO, 2001, p. 313).

A cassação de seu mandato de senador, em 1964, já candidato lançado à Presidência da República, e a suspensão de seus direitos políticos por dez 
anos interromperam, entretanto, o nosso processo democrático e nos levaram ao caos econômico em que hoje nos encontramos. Cassaram não um político. Cassaram um programa de governo que se destinava a dar ao Brasil a independência sonhada desde D. Pedro I (HELIODORO, 2005, p. 35).

Visto que a heroificação do homem Juscelino Kubitschek traduz relações de domínio e poder, a figuração heroica pode ser representada por meio de símbolos, imagens, metáforas e/ou alegorias que sublinham uma vida (privada e/ou pública) como exemplo paradigmático; à qual se acrescentam as qualidades pessoais (tornadas excepcionais) diante de alguma crise, adversidade ou injustiça; a virtú e a fortuna ${ }^{7}$ que servem para desenhar o perfil do governante; as lutas perdidas e/ou as vitórias alcançadas vis-à-vis a dimensão do sacrifício, coragem e abnegação nelas envolvidas; e, até mesmo, a magnanimidade frente aos inimigos e às adversidades.

O herói tombou com a cassação, o exílio, a prisão, a doença e a derrota na ABL que aprofundou, ainda mais, o ostracismo político. Após a morte, contudo, tratava-se de garantir, simbólica e utopicamente, a imortalidade do chefe de Estado, a fim de "arquivar" Juscelino Kubitschek, mormente suas ideias e ações, e preservar o seu corpo a ponto de edificá-lo arquitetonicamente e eternizá-lo, tal qual o horizonte que se descortina por trás do Memorial JK, em Brasília. Apontado como um dos mais belos monumentos do mundo, o memorial foi edificado no ponto mais alto e privilegiado da Capital Federal - o Cruzeiro (onde foi rezada a primeira missa em 1957), em homenagem ao seu fundador e ex-presidente da República Juscelino Kubitschek. É “memória feita em pedra na arquitetura”! (HUYSSEN, 2000, p. 41).

Os restos mortais de JK foram transladados para o memorial, quando da inauguração oficial a 12 de setembro de 1981 - dia do seu aniversário; o que contou, inclusive, com a presença do presidente da República, general João Baptista Figueiredo, que doou o terreno para a construção do monumento graças à luta da viúva Sarah Kubitschek - guardiã da memória (GOMES, 1996) de Juscelino Kubitschek -, com o apoio das filhas, amigos e líderes políticos.

\footnotetext{
${ }^{7}$ O conceito de virtú envolve um conjunto de qualidades e possibilidades que definem a capacidade pessoal e a eficácia política do governante de dominar os eventos e de alcançar um determinado fim para manter o poder e alcançar a honra, o mérito e a glória. O conceito de fortuna envolve a sorte, o acaso, a oportunidade, a influência das circunstâncias no curso dos acontecimentos e que não dependem apenas da vontade humana. $\mathrm{O}$ 'bom governante' deve equilibrar esses dois princípios, ou seja, a virtú e a fortuna, privilegiando a virtú para realizar um bom governo e manter-se no poder e prestando atenção aos sinais da fortuna para agir na oportunidade certa e obter êxito na ação política. Ambos os conceitos, intrinsecamente articulados, relacionam-se à construção e à consolidação de projetos políticos, que podem ser representados, grosso modo, pela figura do governante. (ver Maquiavel, Nicolau. O príncipe. cap. XXV. Rio de Janeiro: Zahar, 2004 \& SKINNER, Q. As fundações do pensamento político moderno. Trad. Renato Janine Ribeiro. São Paulo: Companhia das Letras, 1996.)
} 
A aventura biográfica - a transitar, errante, entre teoria e ficção, documento e literatura - além de conformar, na contemporaneidade, ações de reconhecimento político-cultural, envolve partilha e participação do escritor/narrador, personagem e leitor, pois todos se redescobrem e se refazem. Sendo assim, ao construírem, pela lembrança/esquecimento, a morte-vida do homem JK, tornada texto, os biógrafos Francisco de Assis Barbosa, Carlos Heitor Cony, Affonso Heliodoro, Claudio Bojunga e Ronaldo Costa Couto leem e escrevem o outro e a si, como se estivessem a elaborar mais um "rascunho dos rascunhos" (MIRANDA, 1993, p. 93).

Desse caleidoscópio biográfico, um traço formata as leituras de Juscelino Kubitschek: o heroísmo de um homem de origem humilde que, apesar das marcas do sofrimento, deve permanecer, no terreno movediço da memória coletiva, como um exemplo de luta e uma lição de esperança. Alicerçadas na imagem de um indivíduo heroicizado, as escrituras privilegiam os fortes laços de família; a presença da mãe, Júlia Kubitschek, em detrimento da figura paterna; os atributos pessoais; assim como ressaltam a trajetória política e seus desdobramentos, sem qualificar, criticamente, a dimensão histórico-social do homem-chefe de Estado. Revela-se a vida de um self made man, cuja história permeia e legitima o discurso político mitológico enquanto sacraliza a memória que JK desejou ver arquivada sob o crivo de sua assinatura (DERRIDA, 2001).

Sem dúvida, profundos foram os hiatos entre a utopia do novo Brasil e a realidade atingível do governo Kubitschek, que prometeu avançar o Brasil "Cinquenta anos em Cinco" na vigência da democracia. Não obstante, diante da contundente realidade imposta pelo regime militar, reinstitucionalizado em 1968, com a decretação do AI-5, as escrituras biográficas vêm afirmando, ao revés, a construção de JK como líder político devotado aos negócios de Estado e democrata par excellence, bem como as marcas do nacionaldesenvolvimentismo, minimizando brechas e cisões que questionam a tão aclamada estabilidade política do governo. Por conseguinte, tais biografias expressam - ante a expectativa da síntese de uma trajetória de vida - leituras de $\boldsymbol{o}$ homem Juscelino Kubitschek, seja reproduzindo o corpus identitário definido na autobiografia, seja tomando como referência certos acontecimentos tornados decisivos para respaldar uma experiência pessoal tida como vitoriosa e fascinante.

Entre dizer/ocultar, inscrever/apagar, escrever/ler, as palavras de Cony são corroborantes no sentido de perpetuar a memória de JK e dos cinco anos de seu governo: 
Aos poucos, e ao longo dos anos que se seguiram a seu governo, com a perspectiva criada, sobretudo após as décadas perdidas na economia e as duas décadas de regime totalitário (que foram classificadas de Anos de Chumbo), o período passou a merecer o nome de 'era'. E logo se consagrariam como Anos Dourados, em confronto com os citados Anos de Chumbo.

[...] dormindo profundamente, dias antes de completar 74 anos, morria o homem que seria definido como o contemporâneo do futuro (CONY, 2002, respectivamente p. $87 ; 155)$.

As palavras de Affonso Heliodoro sintetizam e envelopam, nas dobras irregulares do tempo, o trabalho artesanal dos biógrafos:

\begin{abstract}
Deus concedeu-me a glória de trabalhar com JK e a graça de vir a ser o guardião de sua memória. [...] Hoje, na presidência do Instituto Histórico e Geográfico do Distrito Federal, que o tem como Patrono, procuro fazer de minhas tarefas à frente daquela Instituição o mesmo que sempre faço onde quer que esteja: cultuar a memória, proclamar suas excepcionais qualidades de pessoa humana, homem público e político, bem como divulgar seus feitos, sua história, procurando manter viva a imagem do grande brasileiro que foi Juscelino Kubitschek (HELIODORO, 2005, p. 216).
\end{abstract}

Rastrear a dimensão social desse homem e de seu tempo implica compreender como e por que o presente vem forjando - entre permanências e deslocamentos da história - vínculos políticos, ideológicos, utópicos com a década de cinquenta. E, por conseguinte, perceber, na contemporaneidade, os caminhos das disputas que a seleção do que se lembra de e se esquece sobre os Anos JK e o homem público Juscelino Kubitschek abriga.

Da morte e da entrada de JK no monumento erguido em Brasília. Do exílio à volta ao país. Da prisão, da cassação e do isolamento político. Da entrada na política à presidência da República. Do "grande homem público" ao "pobre órfão menino Nonô" - traços identitários que definem as biografias como locus construtor e perpetuador da memória de Juscelino Kubitschek, a (d)enunciar um entrelugar de leituras da história política contemporânea do Brasil sob a lupa da história de um homem.

\title{
Referências bibliográficas:
}

AMARAL, Adriana C. Lopes do. Sobre a memória em Jacques Derrida. In: NASCIMENTO, Evandro; GLENADEL, Paula (Orgs.). Em torno de Jacques Derrida. Rio de Janeiro: 7 Letras, 2000, p. 31-43. 
AVELAR, Idelber. A escrita do luto e a promessa da restituição. In: Alegoria da derrota: a ficção pós-ditatorial e o trabalho de luto na América Latina. Belo Horizonte: Ed. UFMG, 2003, p. 235-259.

BACZKO, Bronislaw. Utopia. In: ROMANO, Ruggiero (Dir.). Enciclopédia Einaudi. Anthropos-homem. Lisboa: Imprensa Nacional-Casa da Moeda, 1985, v. 5, p. 333-396.

BARBOSA, Francisco de Assis. Juscelino Kubitschek: uma revisão na política brasileira. Rio de Janeiro: Guanabara, 1988.

BENJAMIN, Walter. Sobre o conceito da história. In: Magia e técnica, arte e política: ensaios sobre literatura e história da cultura. 7. ed. São Paulo: Brasiliense, 1994. (Obras escolhidas).

BOJUNGA, Claudio. JK: o artista do impossível. Rio de Janeiro: Objetiva, 2001.

CONY, Carlos Heitor. JK: memorial do exílio. Rio de Janeiro: Bloch editores, 1982.

$J K$ : como nasce uma estrela. Rio de Janeiro: Record, 2002.

COUTO, Ronaldo Costa. Brasília Kubitschek de Oliveira. São Paulo; Rio de Janeiro: Record, 2001.

DERRIDA, Jacques. Mal de arquivo: uma impressão freudiana. Rio de Janeiro: Relume Dumará, 2001.

GAGNEBIN, Jeanne Marie. Memória, história, testemunho. In: BRESCIANI, Stella; NAXARA, Márcia (Org.). Memória e (res) sentimento: indagações sobre uma questão sensível. Campinas, SP: Editora Unicamp, 2004, p. 85-94.

GINZBURG, Carlo. Relações de força: história, retórica, prova. São Paulo: Companhia das Letras, 2002.

GOMES, Ângela Maria de Castro. A guardiã da memória. Acervo. Revista do Arquivo Nacional, Rio de Janeiro, v. 9, n. 1/2, p.17-30, jan./dez. 1996.

HAROCHE, Claudine. Elementos para uma antropologia política do ressentimento: laços emocionais e processos políticos. In: BRESCIANI, Stella; NAXARA, Márcia (Orgs.). Memória e (res) sentimento: indagações sobre uma questão sensível. Campinas, SP: Unicamp, 2004, p. 333-349.

HARTOG, François. Tempos do mundo, história; escrita da História. In: GUIMARÃES, Manoel Luiz Salgado (Org.). Estudos sobre a escrita da história: anais do encontro de historiografia e história política. Rio de Janeiro: 7 Letras, 2006, p. 15-25.

HELIODORO, Affonso. JK: exemplo e desafio. 2 ed. Brasília, DF: Thesaurus, 2005.

HUYSSEN, Andreas. Seduzidos pela memória: arquitetura, monumentos, mídia. Rio de Janeiro: Aeroplano, 2000. 
JAMESON, Fredric. Archaelogies of the future: the desire called utopia and other science fictions. London; New York: Verso, 2007.

KOSSELECK, Reinhart. Futuro passado: contribuição à semântica dos tempos históricos. Rio de Janeiro: Ed. PUC-Rio; Contraponto, 2006.

LEVI, Giovanni. Usos da biografia. In: AMADO, Janaína; FERREIRA, Marieta de Moraes (Coords.). Usos e abusos da história oral. Rio de Janeiro: FGV, 1996, p. 167-182.

LEVILLAIN, Philippe. Os protagonistas: da biografia. In: REMOND, René (Org.). Por uma história política. Rio de Janeiro: Editora UFRJ; FGV, 1996, p. 146-184.

MAQUIAVEL, Nicolau. O príncipe. cap. XXV. Rio de Janeiro: Zahar, 2004.

MIRANDA, Wander Melo (Org.). Anos JK: margens da modernidade. São Paulo: Imprensa Oficial do Estado, 2002.

MOTTA, Marly Silva da. O relato biográfico como fonte para a história. Vidya, Santa Maria, RS, n. 34, p. 101-122, jul./dez. 2000.

OLIVEIRA, Juscelino Kubitschek de. Meu caminho para Brasília: a experiência de humildade. Rio de Janeiro: Bloch, 1974, v. I.

. Meu caminho para Brasília: a escalada política. Rio de Janeiro: Bloch, 1976, v. II.

Meu caminho para Brasília: 50 anos em 5. Rio de Janeiro: Bloch, 1978, v. III.

OLIVEIRA, Lúcia Lippi de. Tempos de JK: a construção do futuro e a preservação do passado. In: MIRANDA, Wander Melo (Org.). Anos JK: margens da modernidade. São Paulo: Imprensa Oficial do Estado, 2002, p. 31-43.

POLLAK, Michael. Memória, esquecimento, silêncio. Estudos Históricos, Rio de Janeiro, v. 2, n. 3, p. 3-15, 1989.

ROJAS, Carlos Antonio Rojas. La biografia como género historiográfico: algunas reflexiones sobre sus posibilidades actuales. In: SCHMIDT, Benito Bisso (Org.). O biográfico: perspectivas interdisciplinares. Santa Cruz do Sul, RS: Edunisc, 2000, p. 9-48.

SARLO, Beatriz. Os militares e a história: contra os cães do esquecimento. In: Paisagens imaginárias. São Paulo: Edusp, 2005.

SEIXAS, Jacy Alves de. Os campos (in) elásticos da memória: reflexões sobre a memória histórica. In: __ ; BRESCIANI, Maria Stella; BREPOHL, Marion (Orgs.). Razão e paixão na política. Brasília, DF: Ed. da UNB, 2002, p. 59-77.

SKINNER, Q. As fundações do pensamento político moderno. São Paulo: Companhia das Letras, 1996.

WEINRICH, Harold. Lete: arte e crítica do esquecimento. Rio de Janeiro: Civilização Brasileira, 2001. 
ZIZEK, Slavoj. Introdução: o espectro da ideologia. In: . (Org.). Um mapa da ideologia. Rio de Janeiro: Contraponto, 2007, p. 7-38.

Biographical kaleidoscope: reading Juscelino Kubitschek de Oliveira

\begin{abstract}
This article relates to the political and cultural dimension of the JK Years, through a revisitation of the biographies of the president of the Republic Juscelino Kubitschek, which tell history (ies) within the perplexity of a lifetime. Under a theoretical-methodological approach which underlines the bonds linking history, memory, politics and culture, the study investigates a given reading of present future past, pari passu the construction of this statesman correlatively to the assertive and conservation strategies of his memory. By his turn, the historian should examine the writings of this history and problematize the memory that adorns such past to make it sacred. Therefore, investigating this period under these perspectives, in the long time still so dear to the historian's craft, helps us to grasp how practices and political and cultural experiences weave and determine our lives, either private or public, daring to face the present and draft another history.
\end{abstract}

Key words: History. Memory. Biography. 